\title{
Issues Relating to Trust in Care Agents for the Elderly
}

\author{
Brendan Spillane \\ ADAPT Centre, Trinity College Dublin, Ireland \\ brendan.spillane@adaptcentre.ie \\ Christian Saam \\ ADAPT Centre, Trinity College Dublin, Ireland \\ christian.saam@adaptcentre.ie
}

\begin{abstract}
There is increasing academic interest in and commercial development of care agents to assist with the care of the elderly in the home. This paper defines some of the under-explored questions and issues relating to trust. It raises specific questions to instigate debate and recommends directions for future research in the domain.
\end{abstract}

\section{KEYWORDS}

Home Care Agents, Trust, Elderly Care

ACM Reference Format:

Brendan Spillane, Emer Gilmartin, Christian Saam, and Vincent Wade. 2019. Issues Relating to Trust in Care Agents for the Elderly. In 1st International Conference on Conversational User Interfaces (CUI 2019), August 22-23, 2019, Dublin, Ireland. ACM, New York, NY, USA, Article 4, 3 pages. https://doi. org $/ 10.1145 / 3342775.3342808$

\section{INTRODUCTION}

Trust is one of the biggest factors in the successful adoption of new technologies or services such as home care agents for the elderly [18]. Trust in a care agent can be defined as a perceived value placed on an agent that it will help the trustee achieve their goals $[9,28]$. Whether physical agents, embodied avatars, or disembodied voices, home care agents are designed to provide the elderly, or those otherwise in need of care, with assistance in their day-to-day tasks, monitoring for safety, and social interaction [27]. Rapid population aging, already a factor in much of western Europe and Japan, is now beginning to affect developing nations such as Brazil and China $[3,16]$. Governments, academics, and commercial organizations believe that one method of catering to the needs of the increasing numbers of elderly people is the development of home care agents to enable the elderly to live independently in their homes for longer. This paper delineates and defines some of the problem areas relating to trust to instigate debate and research.

\section{ISSUES AND QUESTIONS OF TRUST}

We discuss eight broad, overlapping, and interconnected areas of concern relating to trust of care agents in the homes of the elderly that are yet to be fully explored.

Permission to make digital or hard copies of part or all of this work for personal or classroom use is granted without fee provided that copies are not made or distributed for profit or commercial advantage and that copies bear this notice and the full citation on the first page. Copyrights for third-party components of this work must be honored.

For all other uses, contact the owner/author(s).

СUI 2019, August 22-23, 2019, Dublin, Ireland

(c) 2019 Copyright held by the owner/author(s)

ACM ISBN 978-1-4503-7187-2/19/08 _\$15.00

https://doi.org/10.1145/3342775.3342808

\author{
Emer Gilmartin \\ ADAPT Centre, Trinity College Dublin, Ireland \\ gilmare@tcd.ie \\ Vincent Wade \\ ADAPT Centre, Trinity College Dublin, Ireland \\ vincent.wade@adaptcentre.ie
}

\subsection{Security}

Many commercial and academic proposals envision home care agents as always on [21], mobile or ubiquitous [24], personalized agents [29], which may be integrated with social media, news feeds, calendars, email, and even health records. Recently there has been greater awareness of the significant security issues with Internet of Things home devices [25]. However the risks relating to lighting, heating, and home appliances pales in comparison to the security risks inherent in many of the envisioned care agents. There is some research being undertaken in this area [5,22], but it has yet to sufficiently analyze all of the issues. At the very minimum, identifying the location of care agents would identify the homes of at risk elderly users who are alone. Other concerns include a single point of access to extensive personal data.

\subsection{Legal Issues}

Legal issues as yet insufficiently explored fall into three categories. The first relates to defining who is the 'user'. Is it the family member or primary carer of the elderly person? Is it the elderly person themselves? This could have significant ramifications on the domain. The second relates to consent. There is insufficient research on elderly users' consent to have such devices in their home. Issues include whether the person the care agent is bought and installed for, is fully aware of the care agent's abilities, especially relating to what personal services it is integrated with, its monitoring facilities, how and where the data is stored, and who has access to it. On the other side of the argument is the end user's cognitive abilities and their care needs. The third category relates to liability. Many of the envisioned commercial and academic care agents aim to undertake tasks such as medication reminders or monitoring of ongoing health issues such as memory decline. They will also store private data and may be connected to the user's social media, email, and other facilities. There are a broad range of issues yet to be explored in the areas of liability. These issues can affect the family or person who bought or installed the care agent in the user's home, the company providing them, and the elderly user. This is further complicated by the fact that the user may have limited cognitive function and may not understand the capabilities of the agent or have fully consented to its installation. This question somewhat mirrors issues around responsibility and liability in the self driving car industry $[12,13]$.

\subsection{Sharing of Personal \& Medical Information}

While care agents may not be explicitly marketed as medical devices, many of the services they aim to provide are in the health domain 
and would usually be provided by a home carer, nurse, or family member. This raises a range of concerns over who has access to an elderly family member's medical data and advice. In Medicine and Law there are established guidelines and practices such as the HIPAA Privacy Rules in the US [8], and Professional Conduct rules which govern medical and legal experts as to what information can be released to or discussed with the family and friends of those in need of care for their best interests. Currently no known guidelines exist for home care agents. Existing research on when, and how patients choose to share information [17] needs to be expanded to include care agents.

\subsection{Privacy and Ethics}

Privacy and ethical concerns are probably the most explored area relating to trust in home care agents $[6,23,33]$. When agents are deployed correctly, the elderly user can perceive home care agents and their monitoring as being necessary to enable them to continue to stay in their homes. However, privacy violations have resulted in shattered trust and requests to stop services [7]. However, there are still many under-explored questions and issues relating to privacy and ethics and their impact on trust in care agents. These include: Who has access to information collected by the care agent? Who has a right to monitor it? What private information can a care agent mine to improve interactions with the person they are caring for? Some of these questions have similarities to the questions and issues faced by parents in relation to monitoring a teenager's phone or Internet access. In both instances they come down to balancing privacy and ethics with whether the person is capable of making independent decisions in their own best interests.

\subsection{Family and Carer Trust in Care Agents}

To the best of our knowledge, no significant research has been undertaken on trust in care agents by the family or primary carers of the elderly. In order for care agents to be successful, the family or primary care givers must have complete trust in its abilities, especially for critical tasks such as medication reminders or fall alerts. Questions which have yet to be explored include: What happens if all the family do not want a care agent installed? Who sets them up? Who is responsible? Who controls settings? What is monitored and stored? Who has access to data and medical updates? These questions are not new. They are an evolution of existing questions and issues many families have to deal with relating to provision of home carers for an elderly parent, or admission to long-term care facilities.

\subsection{A Focus for Distrust?}

Trust is central to acceptance of new technology [18]. Factors which impact trust have been extensively studied to increase adoption $[2,32]$. Major areas of research include: voice characteristics, expression and gesture, personalization, agent persona, and reliability. However, there are still significant gaps in the literature relating to trust. Elements which could impact trust in care agents include: whether the elderly see care agents as being too invasive or as monitors, whether they are seen as a means for their children or family to unburden themselves, or whether they are seen as a sign of their aging, increasing infirmity, or loss of independence. 'Parenting the parent' is a common phenomenon involving a reversal of roles [14]. This should be looked at from the point of view of the parent who may feel a loss of autonomy.

\subsection{What Happens when Trust is Broken?}

Increasingly commercial companies and academics describe a future where care agents are ubiquitous in the homes of the elderly or those otherwise in need of care. Trust is known to be important for successful relationships between the elderly and home care nurses [30]. There is also a significant body of research on how to repair such broken relationships $[15,19]$. It has also been shown that when trust is broken between humans and technology, it turns to distrust, and users will actively avoid the technology or service [11]. However, very little research is being undertaken on what would happen if trust is broken between home care agents and the elderly and and the effect it will have on their use and adoption. What trust repair strategy should be adopted? Will they work?

\subsection{Do the Elderly Actually Want Care Agents?}

While this seems like a relatively simple question, a review of the literature failed to identify any studies specifically asking it. Despite the breadth and depth of studies on embodied and disembodied agents in the home, most studies tend to focus on identifying specific tasks users want help with [20], users expectations of robots roles in their lives [10], expectations of smart home sensors [4], or care agents' usefulness, ease of use, and ability to help the user accomplish tasks [26]. There are many tough questions in elderly care, such as those relating to decisions to leave the home [1], or those relating to palliative care and end of life choices [31] which have all been investigated. Thus it is surprising that such a relatively simple question has not been asked. One possible reason for this is that society and the researchers and commercial companies developing such care agents do not want to know the answer. Care agents are most often seen as a means to monitor, provide company, assist in tasks, and to help aging parents stay in their home. Historically these are the tasks of the children or extended family. However, due to societal changes this is often no longer practical. The development of care agents is seen as a long term cheaper alternative to employing a home carer or putting the elderly into care homes. There are also practical reasons for their development including rapidly aging population in many countries and a decline in the number of young people to care for the elderly. This question is important as it is unlikely that users will ever properly trust agents which they do not actually want in their homes no matter how personalized, useful, friendly or effective they are.

\section{CONCLUSION}

There is little doubt that there will be increased development and use of personalized care agents to aid in the care of the elderly in the home. This paper has defined eight overlapping and interconnected areas where there are significant issues and questions that can affect trust, one of the most important factors for acceptance of a new technology or service. While there is a broad range of research relating to trust in the domain, most of it is focused on identifying methods to increase trust in the agent rather than larger issues. 


\section{ACKNOWLEDGMENTS}

This research is supported by the Science Foundation Ireland (Grant 13/RC/2106) and the ADAPT Centre (www.adaptcentre.ie) at Trinity College, Dublin.

\section{REFERENCES}

[1] François Béland. 1984. The Decision of Elderly Persons to Leave Their Homes. The Gerontologist 24, 2 (Apr 1984), 179-185. https://doi.org/10.1093/geront/24.2.179

[2] Timothy Bickmore and Justine Cassell. 2001. Relational Agents: A Model and Implementation of Building User Trust. ACM, 396-403. https://doi.org/10.1145/ 365024.365304

[3] Feinian Chen and Guangya Liu. 2009. Population aging in China. In International handbook of population aging. Springer, 157-172.

[4] George Demiris, Brian K. Hensel, Marjorie Skubic, and Marilyn Rantz. 2008 Senior residents' perceived need of and preferences for "smart home" sensor technologies. International fournal of Technology Assessment in Health Care 24, 1 (Jan 2008), 120-124. https://doi.org/10.1017/S0266462307080154

[5] Tamara Denning, Cynthia Matuszek, Karl Koscher, Joshua R. Smith, and Tadayoshi Kohno. 2009. A Spotlight on Security and Privacy Risks with Future Household Robots: Attacks and Lessons. In Proceedings of the 11th International Conference on Ubiquitous Computing (UbiComp '09). ACM, 105-114. https://doi.org/10.1145/1620545.1620564 event-place: Orlando, Florida, USA.

[6] Heather Draper and Tom Sorell. 2017. Ethical values and social care robots for older people: an international qualitative study. Ethics and Information Technology 19, 1 (Mar 2017), 49-68. https://doi.org/10.1007/s10676-016-9413-1

[7] Anna Essén. 2008. The two facets of electronic care surveillance: An exploration of the views of older people who live with monitoring devices. Social Science \& Medicine 67, 1 (Jul 2008), 128-136. https://doi.org/10.1016/j.socscimed.2008.03.005

[8] Office for Civil Rights (OCR). 2008. The HIPAA Privacy Rule. (May 2008). https://www.hhs.gov/hipaa/for-professionals/privacy/index.html

[9] A. Freedy, E. DeVisser, G. Weltman, and N. Coeyman. 2007. Measurement of trust in human-robot collaboration. In 2007 International Symposium on Collaborative Technologies and Systems. 106-114. https://doi.org/10.1109/CTS.2007.4621745

[10] Susanne Frennert, Hákan Eftring, and Britt Östlund. 2013. What Older People Expect of Robots: A Mixed Methods Approach. In Social Robotics (Lecture Notes in Computer Science), Guido Herrmann, Martin J. Pearson, Alexander Lenz, Paul Bremner, Adam Spiers, and UteEditors Leonards (Eds.). Springer International Publishing, 19-29.

[11] David Gefen, Izak Benbasat, and Paula Pavlou. 2008. A Research Agenda for Trust in Online Environments. Fournal of Management Information Systems 24, 4 (Apr 2008), 275-286. https://doi.org/10.2753/MIS0742-1222240411

[12] Sabine Gless, Emily Silverman, and Thomas Weigend. 2016. If Robots cause harm, Who is to blame? Self-driving Cars and Criminal Liability. New Criminal Law Review: In International and Interdisciplinary fournal 19, 3 (2016), 412-436.

[13] Alexander Hevelke and Julian Nida-Rümelin. 2015. Responsibility for crashes of autonomous vehicles: an ethical analysis. Science and engineering ethics 21, 3 (2015), 619-630.

[14] Lois Keith and Jenny Morris. 1995. Easy targets: a disability rights perspective on the'children as carers' debate. Critical Social Policy 15, 44-45 (1995), 36-57.

[15] Roy J. Lewicki and Chad Brinsfield. 2017. Trust Repair. Annual Review of Organizational Psychology and Organizational Behavior 4, 1 (2017), 287-313. https://doi.org/10.1146/annurev-orgpsych-032516-113147

[16] Gabriella Morais Duarte Miranda, Antonio da Cruz Gouveia Mendes, and Ana Lucia Andrade da Silva. 2016. Population aging in Brazil: current and future social challenges and consequences. Revista Brasileira de Geriatria e Gerontologia 19, 3 (2016), 507-519.

[17] Leysan Nurgalieva, Alisa Frik, Francesco Ceschel, Serge Egelman, and Maurizio Marchese. 2019. Information Design in An Aged Care Context. (2019), 11.

[18] Paul A. Pavlou. 2003. Consumer acceptance of electronic commerce: Integrating trust and risk with the technology acceptance model. International fournal of Electronic Commerce 7 (2003), 101-134. https://doi.org/10.1080/10864415.2003. 11044275

[19] Daniel B. Quinn, Richard Pak, and Ewart J. de Visser. 2017. Testing the Efficacy of Human-Human Trust Repair Strategies with Machines. Proceedings of the Human Factors and Ergonomics Society Annual Meeting 61, 1 (Sep 2017), 1794-1798. https://doi.org/10.1177/1541931213601930

[20] C. Ray, F. Mondada, and R. Siegwart. 2008. What do people expect from robots?. In 2008 IEEE/RSF International Conference on Intelligent Robots and Systems. 38163821. https://doi.org/10.1109/IROS.2008.4650714

[21] Carsten Röcker. 2011. Designing ambient assisted living applications: An overview over state-of-the-art implementation concepts. In International Conference on Modeling, Simulation and Control IPCSIT, Singapore, Vol. 10. 167-172.

[22] Matthew Rueben and William D Smart. 2016. Privacy in Human-Robot Interaction: Survey and Future Work. (2016), 43
[23] Amanda Sharkey and Noel Sharkey. 2012. Granny and the robots: ethical issues in robot care for the elderly. Ethics and Information Technology 14, 1 (Mar 2012), 27-40. https://doi.org/10.1007/s10676-010-9234-6

[24] Mikhail Simonov, Marco Bazzani, and Antonella Frisiello. 2012. Ubiquitous monitoring \& service robots for care. In 35th German conference on artificial intelligence September, Saarbrucken, Germany. 24-27.

[25] V. Sivaraman, H. H. Gharakheili, A. Vishwanath, R. Boreli, and O. Mehani. 2015. Network-level security and privacy control for smart-home IoT devices. In 2015 IEEE 11th International Conference on Wireless and Mobile Computing, Networking and Communications (WiMob). 163-167. https://doi.org/10.1109/WiMOB.2015. 7347956

[26] Cory-Ann Smarr, Tracy L. Mitzner, Jenay M. Beer, Akanksha Prakash, Tiffany L. Chen, Charles C. Kemp, and Wendy A. Rogers. 2014. Domestic Robots for Older Adults: Attitudes, Preferences, and Potential. International fournal of Social Robotics 6, 2 (Apr 2014), 229-247. https://doi.org/10.1007/s12369-013-0220-0

[27] Brendan Spillane, Emer Gilmartin, Christian Saam, Ketong Su, Benjamin R Cowan, Séamus Lawless, and Vincent Wade. 2017. Introducing ADELE: A personalized intelligent companion. In Proceedings of the 1st ACM SIGCHI International Workshop on Investigating Social Interactions with Artificial Agents. ACM, 43-44.

[28] Mariarosaria Taddeo. 2010. Modelling Trust in Artificial Agents, A First Step Toward the Analysis of e-Trust. Minds and Machines 20, 2 (Jul 2010), 243-257. https://doi.org/10.1007/s11023-010-9201-3

[29] Seiki Tokunaga, Kazunari Tamamizu, Sachio Saiki, Masahide Nakamura, and Kiyoshi Yasuda. 2017. VirtualCareGiver: Personalized smart elderly care. International Journal of Software Innovation (IFSI) 5, 1 (2017), 30-43.

[30] Lorraine Trojan and Olive Yonge. 1993. Developing trusting, caring relationships: home care nurses and elderly clients. fournal of Advanced Nursing 18, 12 (1993), 1903-1910

[31] Raymond Voltz, Akira Akabayashi, Carol Reese, Gen Ohi, and Hans-Martin Sass. 1998. End-of-Life Decisions and Advance Directives in Palliative Care: A Cross-Cultural Survey of Patients and Health-Care Professionals. Fournal of Pain and Symptom Management 16, 3 (Sep 1998), 153-162. https://doi.org/10.1016/ S0885-3924(98)00067-0

[32] Beste F. Yuksel, Penny Collisson, and Mary Czerwinski. 2017. Brains or Beauty: How to Engender Trust in User-Agent Interactions. ACM Transactions on Internet Technology 17, 1 (Jan 2017), 1-20. https://doi.org/10.1145/2998572

[33] Sandra A. Zwijsen, Alistair R. Niemeijer, and Cees M. P. M. Hertogh. 2011. Ethics of using assistive technology in the care for community-dwelling elderly people: An overview of the literature. Aging \& Mental Health 15, 4 (May 2011), 419-427. https://doi.org/10.1080/13607863.2010.543662 